\title{
Characterization and Modeling of the Mechanical Behavior of Aeronautical Alloy Based Composite
}

\author{
A. Sadki ${ }^{1, *}$, M.L.Hattali ${ }^{2}$, M. A. Bradai ${ }^{3}$, R. Younes ${ }^{3}$, N.Mesrati ${ }^{1,4}$ \\ ${ }^{1}$ Laboratory of Sciences and Materials Engineering, National Polytechnic School of Algiers, Algeria \\ ${ }^{2}$ Laboratoire FAST, Université Paris-Sud, Université Paris-Saclay, France \\ ${ }^{3}$ Laboratory of Mechanics, Materials and Energetic, Faculty of Technology, University of Bejaia, Algeria \\ ${ }^{4}$ Higher School of Aeronautical Technical, Algeria
}

Copyright $\bigcirc 2016$ by authors, all rights reserved. Authors agree that this article remains permanently open access under the terms of the Creative Commons Attribution License 4.0 International License

\begin{abstract}
This work focuses on the experimental characterization and mechanical behavior modeling of aeronautical alloy based composite to simulate tension test by finite element method and experimental test. The numerical finite element simulation allowed us to understand and manage a number of phenomena encountered during the mechanical behavior of our composites. Tensile tests applied have shown large changes in mechanical properties of the base alloy after coating, which are possibly related to the very different nature of the assembled materials and conditions of application. We note a strong decrease of the elastic limit of AG3 coated compared to AU4G. The high ductility of this alloy is the cause which engenders during the gritting process a large penetration of the granule particles in the substrate and the creation of plastic zones. Thus, a radial compression is exerted on the section which causes a plastification process. The decrease of the average section of the substrate after sandblasting, the stress concentration at the cavity and / or the compressive residual stress created when sandblasting are responsible for the decrease in breaking strength of the AU4G compared to the AG3. The material becomes hard and fragile. The experimental results obtained during our study are consistent with those of the simulation. Indeed, it was noted that the concentration of stresses during the tensile tests was located at the ends of the useful length of the test specimen.
\end{abstract}

Keywords Aeronautical, Coatings, Aluminum, Mechanical Behavior

\section{Introduction}

Wire arc spraying is an inexpensive thermal spray deposition process in which the materials to be deposited through wires are in the form of consumable arc electrodes. Low running costs, high deposition rates, and efficiency make it a good process for spraying large areas. Recent equipments and process developments have improved the quality and expanded the potential application range for arc sprayed coatings. Typical general applications are thermal barriers, wear resistance, corrosion resistance, high dielectric strength, hard dense coatings, and decorative arts. Al alloy arc sprayed coatings also provide excellent resistance to atmospheric corrosion and are used on bridges and other infrastructure components [1-3]

Aluminum alloys lend themselves to many engineering applications because of their improved mechanical properties offer great advantages for use in aerostructures through density reduction, stiffness increase, increases in fracture toughness and fatigue crack growth resistance and low cost. The main applications of these materials are in aeronautical, automotive and food industries [4-7]. The manufacture of aluminum isn't enough due to the losing of material through edge cracking during the hot rolling process which is applied to reduce thick billets of as-cast material.

Austenitic stainless steels are used in numerous industrial applications, mainly due to their excellent corrosion resistance in different environments. It is connected with adherent and self-healing passive film on the surface and thus received growing attention in nuclear and petrochemical industries, pulp and paper chemical, food and chemical processing and biomedical industries. However, good tribological and mechanical properties of coating austenitic stainless steels in terms of abrasion resistance limited their applications in engineering fields. Corrosion, erosion and wear related problems occur. The problem has been reported to affect static equipment for example pipelines, valves, heat exchangers, pressure vessels and various rotating equipment namely compressors, turbines and pumps. Appropriate material selection and careful material characterisation are very important in any engineering applications.

The use of coatings is one of the most effective strategies to protect materials against corrosion and to increase the wear resistance of materials. This allows for developing 
components with optimized surface behavior using cheaper or more processable materials, like mild carbon steel. Different coating alternatives of carbon steel can be found in the literature: stainless steel $[8,9]$ organic coatings $[10,11]$ ceramic coatings $[12,13]$ and cermets $[14,15]$. In recent years, sprayed aluminum alloys are used in a high technology of aeronautics, e.g., as bond coats for thermal barrier coatings on turbine components, as restorative layers for machine parts, for corrosion under pressure, in numerous other applications requiring wear, high temperature and corrosion-resistant surfaces [16-21]. The purpose of coatings is to protect the surface of the machine element from attacks. Whatever the good reliability of coating required strong adhesion with substrate.

The aim of the present paper is to study the successful application of stainless steel coatings onto two different substrate aluminum alloys AG3 and AU4G by using arc spraying process. In this goal, two types of composite systems, (I) and (II), have been prepared: (I): Thermanite (ASTM 301) Coating / Bond coat 75E / Substrate AG3) and (II) (Thermanite (ASTM 301) Coating / Bond coat 75E / Substrate AU4G). The microstructure coatings were analyzed by optical microscopy $(\mathrm{OM})$ and scanning electron microscope (SEM). The adhesion test of coatings was evaluated using a tensile test and interface toughness stress was determined by numerical simulation tests in order to determine interfacial strength of stainless steel coatings

\section{Experimental Details}

\subsection{Materials and Spraying Parameters}

The present investigation has been carried out employing two different substrate based aluminum alloys with different chemical compositions. It was provided by the Aerospace Equipment Retrofit Unit (ERMA). The first one is AU4G (ASTM 2017A) used in the construction of aircraft fuselage and wing airplane; in particular for parts subjected to different stress. The second is aluminum alloys AG3 (ASTM 5457); this alloy is softer than the AU4G but is used in bodywork. Formed in the annealed condition, it can be welded by various processes. This chemical composition of substrates was obtained by using analysis X-rays fluorescence as is shown in table 1 .

Table 1. Chemical composition of substrates.

\begin{tabular}{|c|c|c|c|c|c|}
\hline Elements & Al \% & Cu \% & Cr \% & Mn \% & Mg \% \\
\hline $\begin{array}{c}\text { AU4G } \\
(2017 A)\end{array}$ & 94.3 & 4 & 0.5 & 0.5 & 0.7 \\
\hline AG3 (5457) & 96.3 & - & 0.3 & 0.3 & 3.1 \\
\hline
\end{tabular}

Before the coating process, the surface of the substrate was grit blasted with corundum particles of $99,50 \mathrm{wt} \%$ purity and $0,5 \mathrm{~mm}$ mean particle size, using an air of $0,4 \mathrm{MPa}$, an incidence angle of 90 and a gun-to-substrate distance of $150 \mathrm{~mm}$. The surface was then cleaned and degreased using acetone within an ultrasonic bath. The grit blasted substrates was carried out in order to increase the surface roughness of the samples and improve the mechanical bonding of the coating to be deposited. The surface roughness of the grit blasted specimens was found to increase from $\mathrm{Ra} \sim 0.09 \mu \mathrm{m}$ to $\mathrm{Ra} \sim 3.33 \mu \mathrm{m}$.

Table 2. Chemical composition of the different used materials.

\begin{tabular}{|c|c|c|c|c|c|c|}
\hline Elements & Al & $\mathbf{C}$ & $\mathbf{N i}$ & $\mathbf{C r}$ & $\mathbf{M n}$ & $\mathbf{F e}$ \\
\hline $\begin{array}{c}\text { Bond coat } \\
\text { (75E) }\end{array}$ & 19.4 & - & 79.2 & $/$ & $/$ & $/$ \\
\hline $\begin{array}{c}\text { Thermanite } \\
\text { (ASTM 301) } \\
\text { Coating }\end{array}$ & - & 0.132 & 5 & 18 & 8 & Balance \\
\hline
\end{tabular}

The roughness measurements to determine surface roughness profile of each substrate were made with a profilometry (Hommel tester T500). It is an optical metrology equipment used to study surface topography. It is carried out over $25 \mathrm{~mm}$ stylus tracing length, collecting 14000 data points per measurement. The development of coatings required to use a gun flame-wire electric Arc spray 234 (Metal Spary Co. Ltd, Aukland, New Zealand). The thickness of this coating was approximately $600 \mu \mathrm{m}$. During projection, the gun is positioned perpendicular to the surface of the substrates at a controlled distance of about $150 \mathrm{~mm}$. A compressed air jet located about $80 \mathrm{~mm}$ from the sample is directed to the surface of the deposit after the projection, to control cooling. The mechanical and physical properties of the used materials and the spray parameters used are given in Table 3.

\begin{tabular}{|c|c|}
\hline \\
\hline Coating
\end{tabular}




\subsection{Micro Structural Characterization}

Microstructures of coatings were observed on a (QUANTA 600FEI) scanning electron microscope (SEM) of QUANTA coupled with energy dispersive X-ray analyzer, which allows a correspondence of image observation and chemical analysis. The coating thickness was measured by taking back scattered electron image (BSEI). The beam size is typically on the order of $1 \mu \mathrm{m}$, and a typical detection limit is $\leq 1$ at $\%$, and thus, we anticipated that this method might provide information on the extent of homogenization achieved during the thermal spraying.

\subsection{Mechanical Behavior}

\subsubsection{Tensile Tests}

Dumbbell-shaped specimens, $4 \mathrm{~mm}$ thick, were machined from casted plates and tested according to DIN EN ISO 527 using a universal testing machine (Zwick 1474) at room temperature and at a crosshead speed of $0.5 \mathrm{~mm} / \mathrm{min}$. The displacement of each specimen during tension was accurately measured by an extensometer with an initial gage length of $20 \mathrm{~mm}$.

The mechanical tests were carried out on a tension-compression machine Zwick / Roell kind Zmart-PRO with a load of $200 \mathrm{KN}$ which simultaneously manages the acquisition time (s) of the applied force $(\mathrm{N})$ and the displacement beam $(\mathrm{mm})$. The applied force is measured by a series-connected power gauge between the frame and the mobile jaw. Thanks to the clamping jaws, the translating movement of the mobile cross member causes the deformation of the specimen. Software (Xpert II Test) data acquisition and control of the machine is installed on a computer by serial communication with the test machine. This program processes and records the data from the various sensors of the machine in order to have all deformation, displacement values) during a test. All the elements involved in achieving the uniaxial tensile tests and data acquisition are shown schematically in Figure 2 and 3.

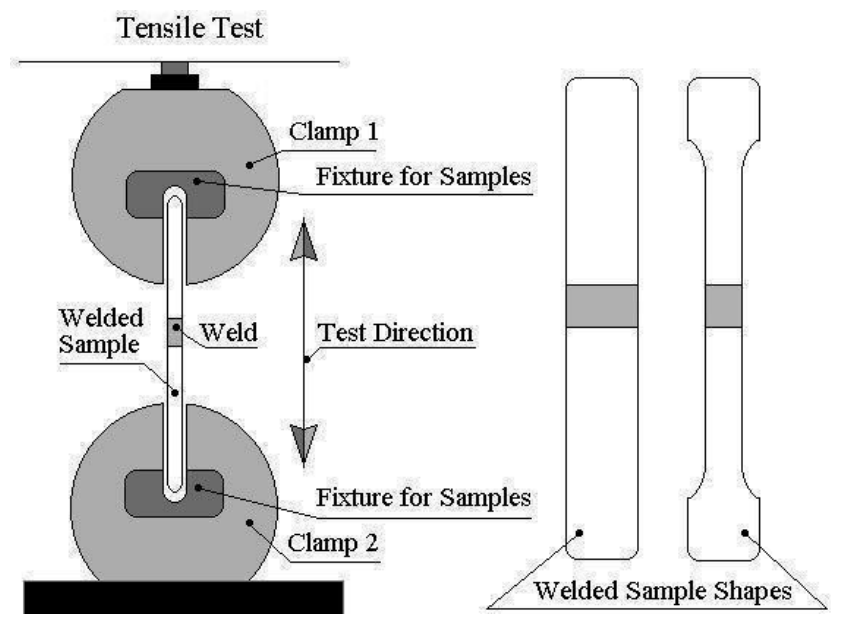

Figure 2. Principle of tensile test Zwick / Roell kind Zmart-PRO.
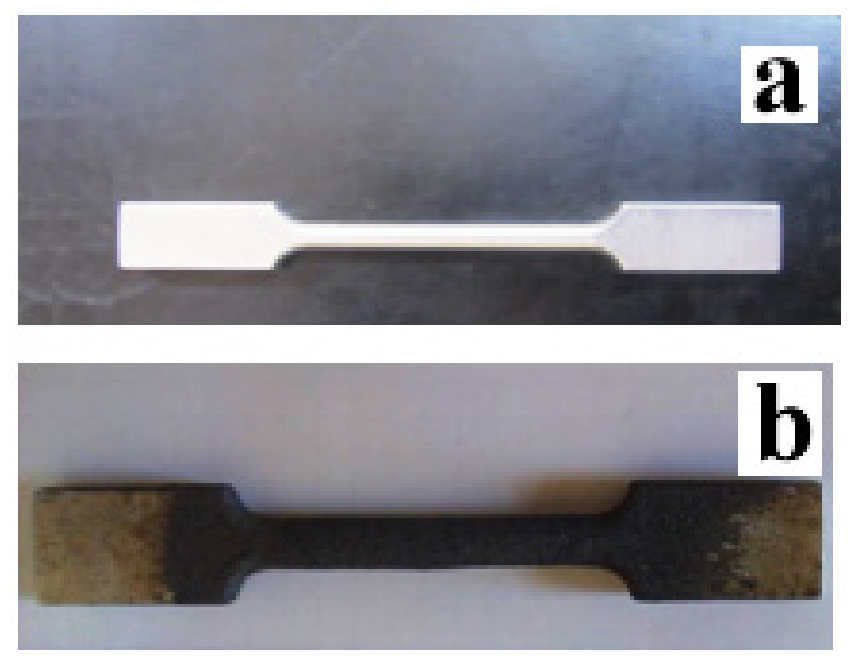

Figure 3. Sample of tensile test a) uncoated, b) As-sprayed.

\subsubsection{The Numerical Modelisation of Tensile Test}

The displacement and deformation behaviors of aeronautical alloy are studied in this section [13-15]. Numerical method for predicting a material property has been developed in order to solve numerically the tensile strength deformation and displacement of coating realized ... etc. The modeling process was made so that the same experimental parameters are respected. The contribution to the numerical modeling of ownership of the deposit in need is:

- The Poisson's ratio of the material. The material can be considered as linear elastic;

- The geometry of the final which has to be meshed using tetrahedron elements, finite element model

development, with the execution of convergence tests, has been followed;

- The boundary conditions are just sufficient to block rigid body motion. This means that real boundary conditions, which are applied during tensile test, and are produced in the solving code.

\section{Results and Discussion}

\subsection{Microstructure Investigation}

Fig.4 shows typical cross-sectional morphology of thermanite coating with typical lamellar steel splats, unmelted particles, oxides, inclusions, micro-cracks and pores. Unmelted particles are identified in the coating by their size and near-spherical morphology similar to that shown in Figure.5. Melted and re-solidified particles have a featureless appearance while unmelted particles. The oxides are probably formed due to the oxidation in-flight particles between successive runs and have appeared in the microstructure in the form of intersplat lamellae or globules. 


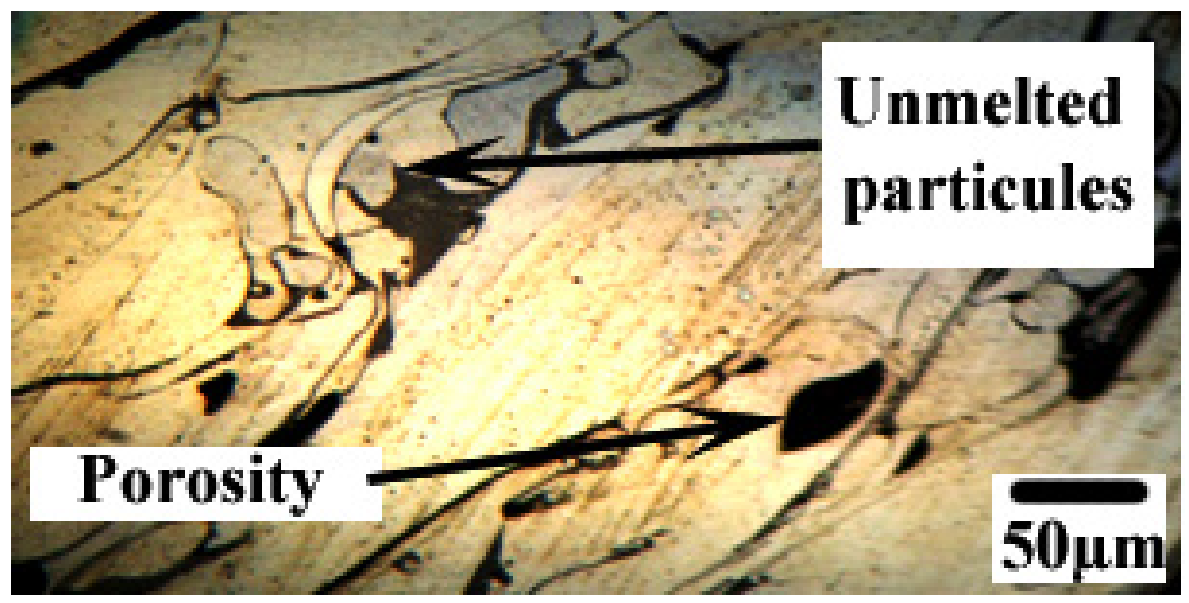

Figure 4. Micrography of thermanite (ASTM 301) coating.

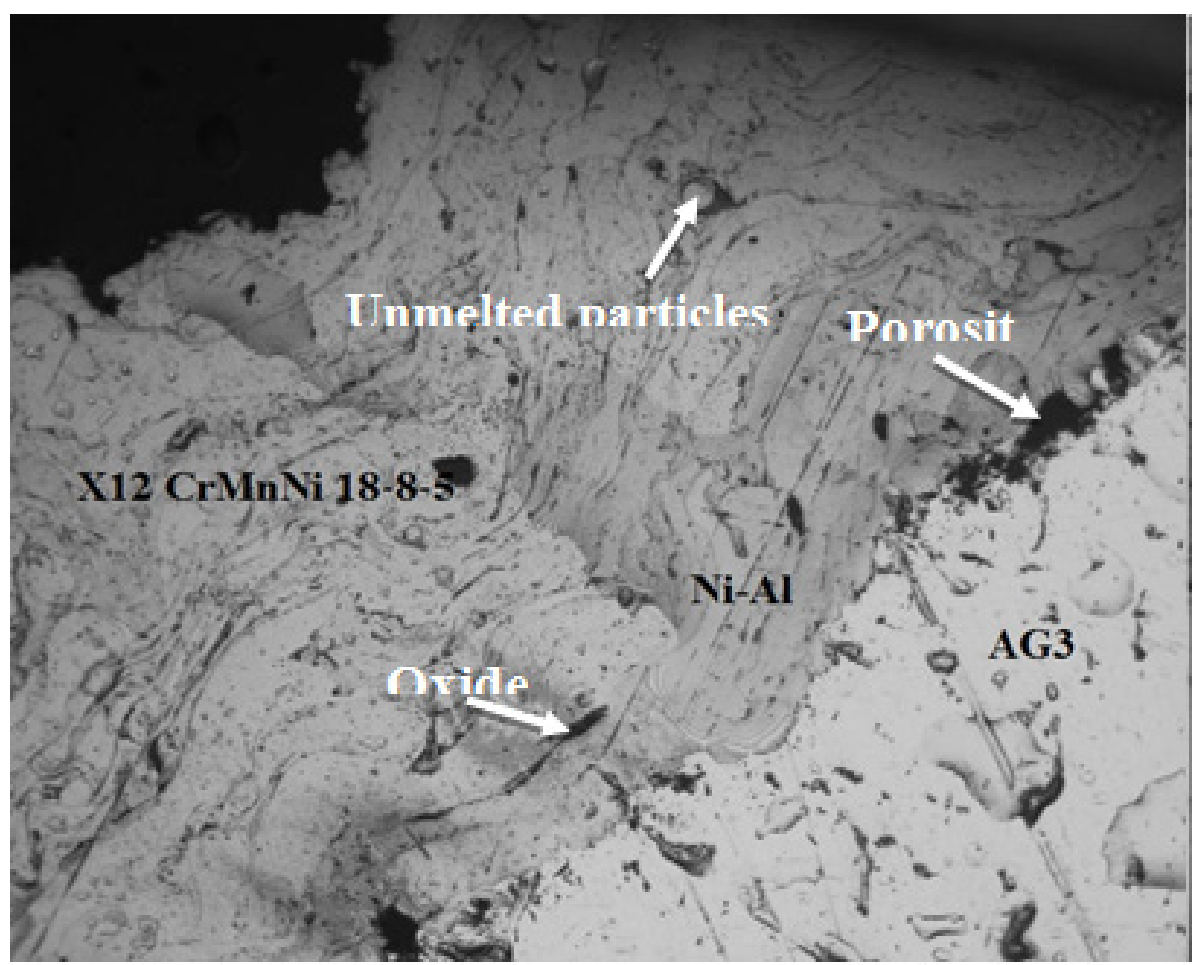

a) 


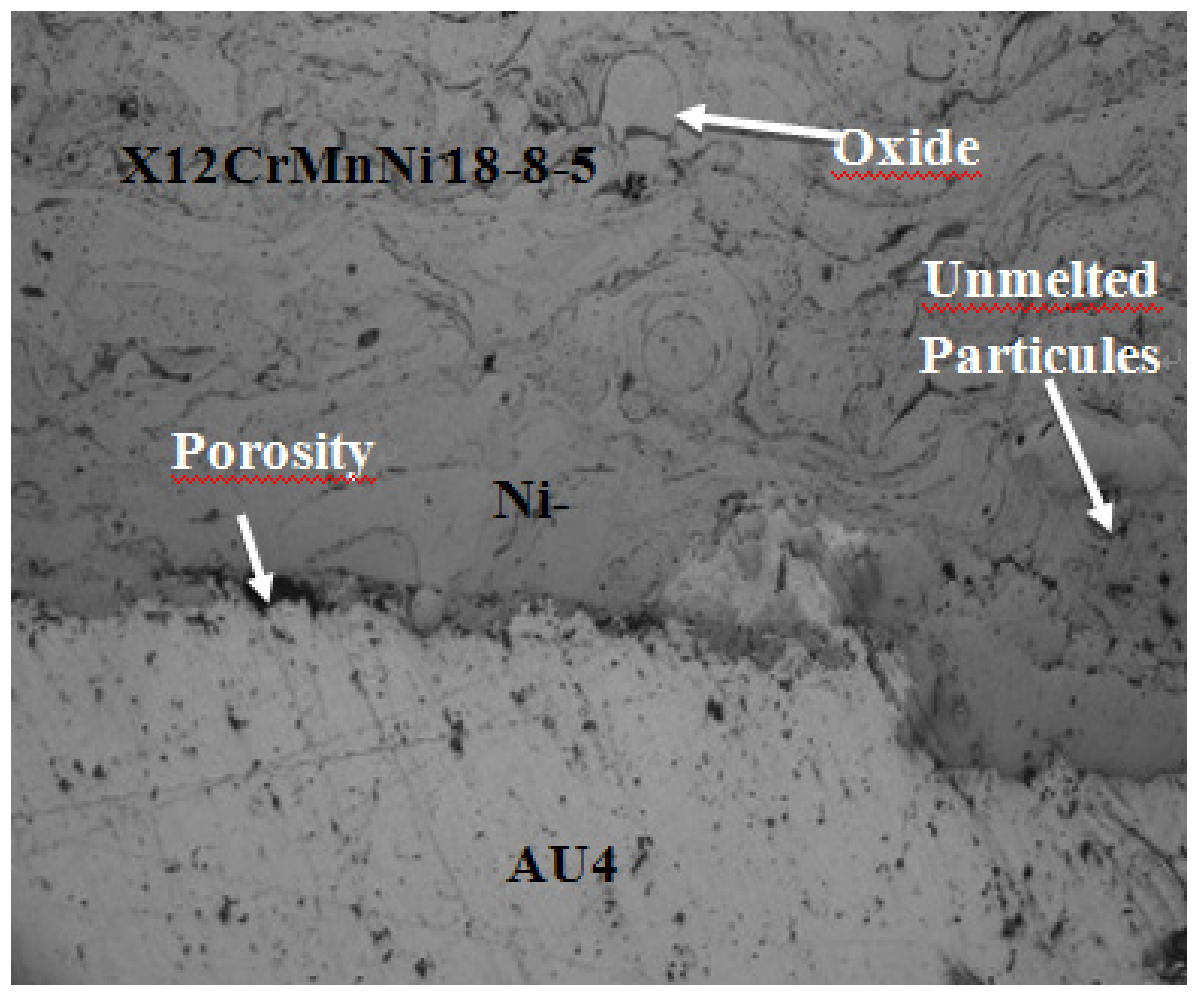

b)

Figure 5. Micrograph of two system coating before mechanical test: a) system 1, b) system 2 .

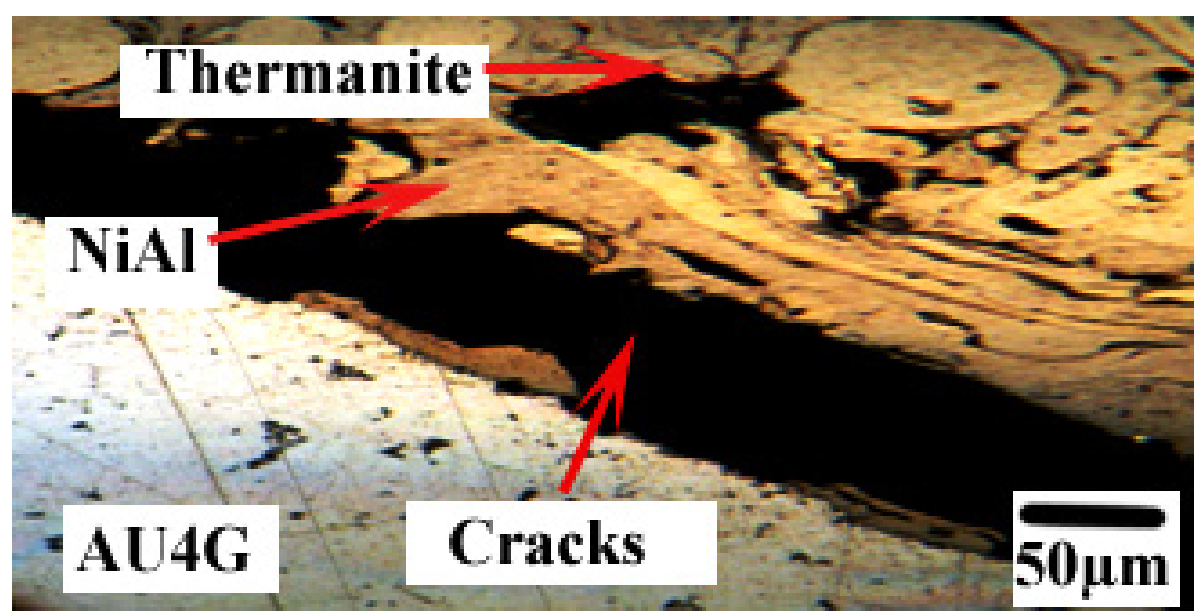

Figure 6. Micrograph of two system coating after mechanical test: system 2.

Micrographic of typical cross-sectional morphology of both composite coating alloys (Figure.6) before the tensile stress showed that:

- The multilayered coatings have homogenous lamellae;

- The morphology shows a good adhesion shape between bond-coat and substrates.

- The presence of several phases complexes in the coating and the bon coat.

- No structural changes have appeared at the interfaces of the system 1 or system 2 respectively.

- The presence of oxide particles on system AU4G/NiAl/Theramite are more than AG3/NiAl/Theramite.
The coating has a good adhesion on the blasted surface of different aluminum alloys substrates which is due to the great energy kinetic of molten particles (Thermanite) generated onto substrates. The impact of these particles on the different substrates permits good spreading on the rugosity due to by blasting process.

The nice adhesion between coating and substrate and the absence of structural changement at the interface of the AG3/AU4G show can be explained by:

1. The formation of alumina $\mathrm{Al}_{2} \mathrm{O}_{3}$ on the surface of the feedstock due to the absence of post-treatment before arc spraying process (ASP).

2. The absence of preheating of the reach surface of 
coating caused and difference between coefficients of dilation between materials used.

The $\mathrm{Al}_{2} \mathrm{O}_{3}$ oxide layer on the substrate the $\mathrm{AU} 4 \mathrm{G}$ is more important than on the substrates AG3, because of the composition of alloys: the $\mathrm{AlMg}_{3}$ compound is very important and prevents and don't allow appearance of $\mathrm{Al}_{2} \mathrm{O}_{3}$, which is not the case for AU4G alloy.

After mechanical test, we note a large breaking all along the interface between the substrate and coating, the appearance of cracks at the interface returns mainly to:

- The presence of alumina $\left(\mathrm{Al}_{2} \mathrm{O}_{3}\right)$, which acts as a diffusion barrier between the substrate and the coating and alumina is hard particle which can be present a brittle breaking on interface and decrease a reliability of coating.

- Striction, Necking, which is the constricting the sample coated under tensile stress which is the primary phenomenon of crack initiation on especially as coating,

\subsection{Tensil Test of Multimaterials}

\subsubsection{Tensil Test of Multimaterials AU4G/NiAl/Thermanite}

Figure 7 depicted the results of tensil test of System 2 which is composed by Thermanite (ASTM 301) Coating / Bond coat 75E / Substrate AU4G.

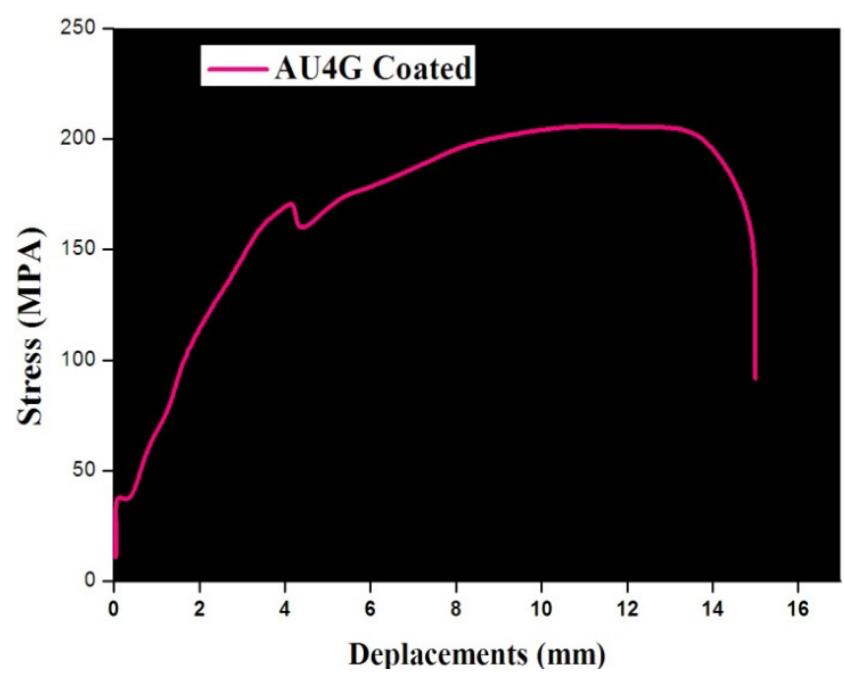

Figure 7. Tensile test of AU4G coated

The curve relating to results of tensile test of System 2: Thermanite (ASTM 301) Coating / Bond coat 75E / Substrate AU4G (figure 8) shows a very similar appearance to conventional traction curves, it is characterized by three levels of behavior of material under loading. Nevertheless, in beginning of elastic curve, we remark changes of stress value which is probably due of coatings delamination. In order to identify the mechanical behavior of the applied coating, it must to compare mechanical behavior of materials with and without coating in order to obtain a finally results.
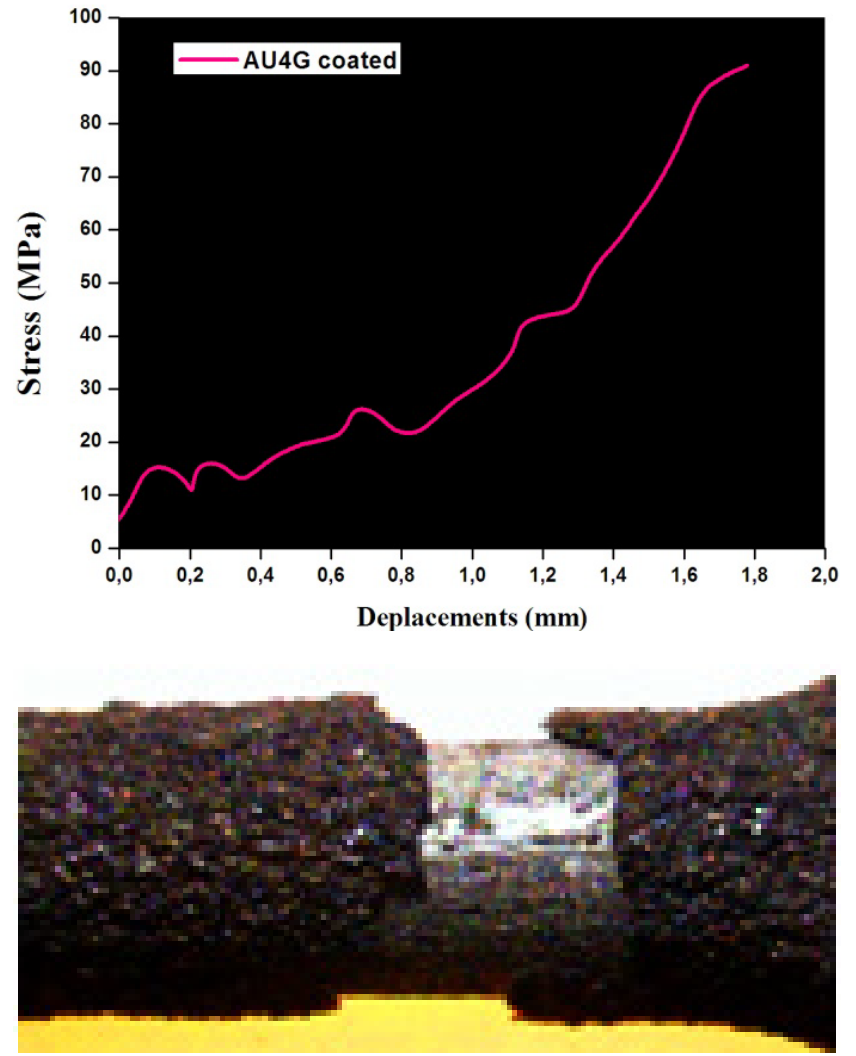

Figure 8. Breaking of the composite system 2 .

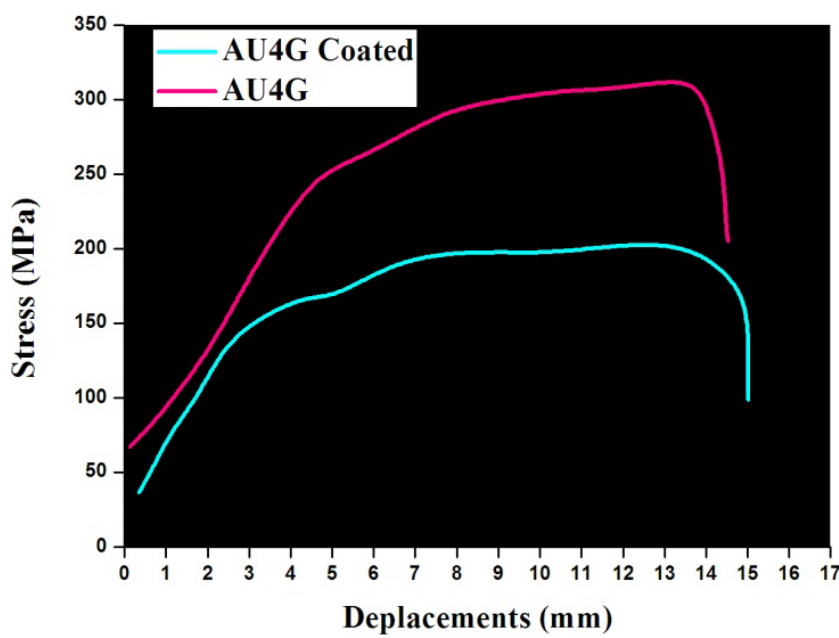

Figure 9. Comparative study of tensile test $\mathrm{AU} 4 \mathrm{G}$ and $\mathrm{AU} 4 \mathrm{G}$ coated

The two curves stress-strain of AU4G uncoated and AU4G coated showed several changes as regards the mechanical properties, For AU4G uncoated, the yield strength decreased from $R_{e}=201 \mathrm{MPa}$ to $R_{e}=165 \mathrm{MPa}$. The fracture stress, fall from $R_{p}=262 \mathrm{MPa}$ for AU4G uncoated to $\mathrm{R}_{\mathrm{p}}=206 \mathrm{MPa}$ for coated AU4G. We remark also stretching $\mathrm{A} \%$ has been constant during time of tensile test, However, for AU4G coated we note the appearing of low variation in the plastic deformation levels.

The variation (fluctuation) presented by the curve in Figure. 9 can be due to the appearance of a crack in the coating under loading $\sigma=165 \mathrm{MPa}$. 
The changes came in the plastic deformation zone of the AU4G curve are less than to deformation which happened in tensile stress presented at $165 \mathrm{MPa}$, and they are probably due to their micro cracks presents in the coating. This decreasing of tensile strength in the coated substrate, compared to the substrate is mainly owing to the stress concentration at the cavity created by blasting corundum.

\subsubsection{Tensil Test of Multimaterials AG3/NiAl/Thermanite}

Figure.10 depicted the results of tensile test of System 1: Thermanite (ASTM 301) Coating / Bond coat 75E / Substrate AG3

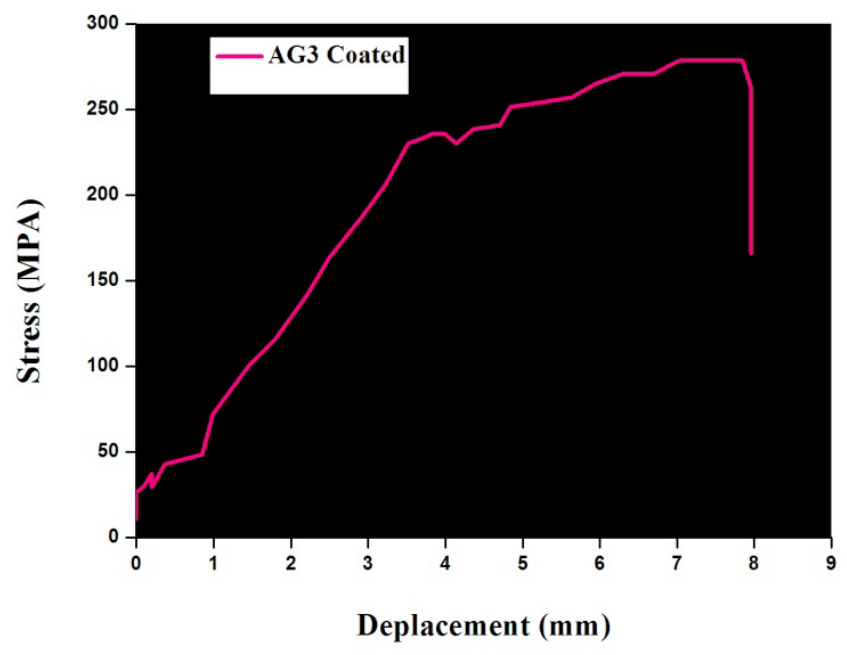

Figure 10. Tensile test of AG3 coated.
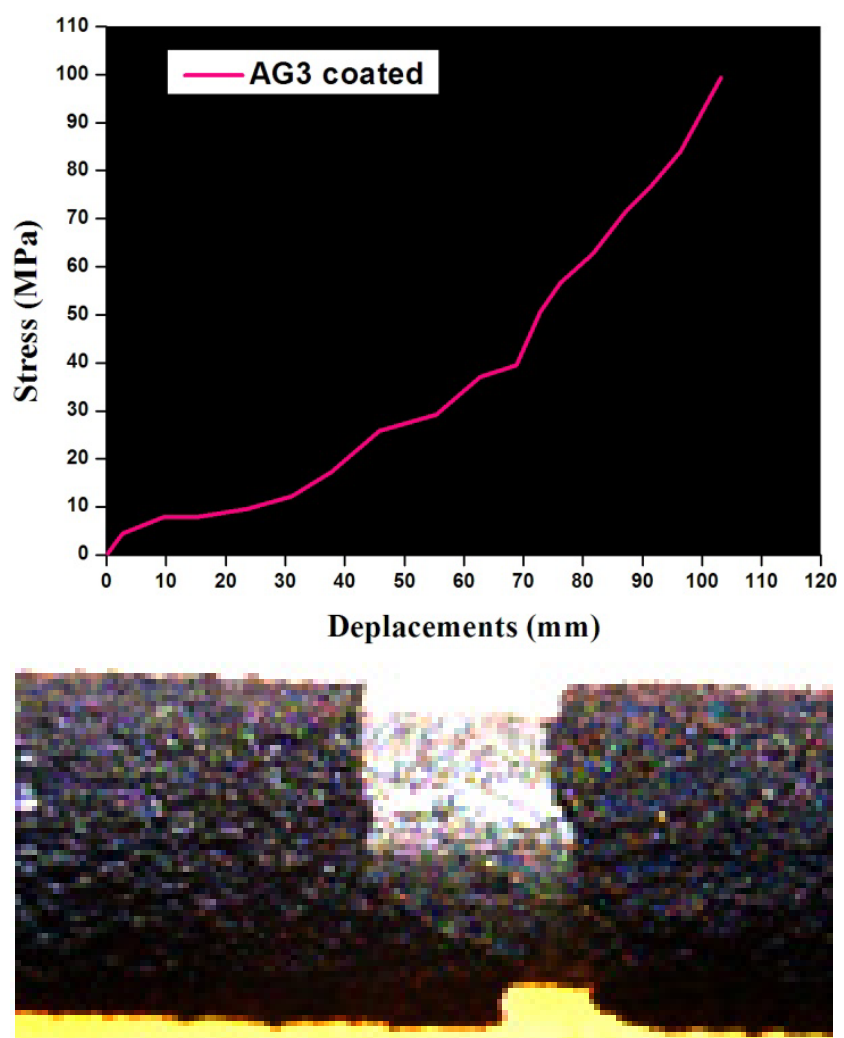

Figure 11. Breaking of the composite system 1 .
The curve relating to results of tensile test of System 1: Thermanite (ASTM 301) Coating / Bond coat 75E / Substrate AG3 (Figure 11) shows a very similar shape to tensile test curves; it is characterized by three levels of reaction of the material under loading. Nevertheless, in beginning of elastic curve, we remark that after the yield strength $(\mathrm{Re})$ a variation of the curve along the plastic part until the fracture of simple AG3 coated.

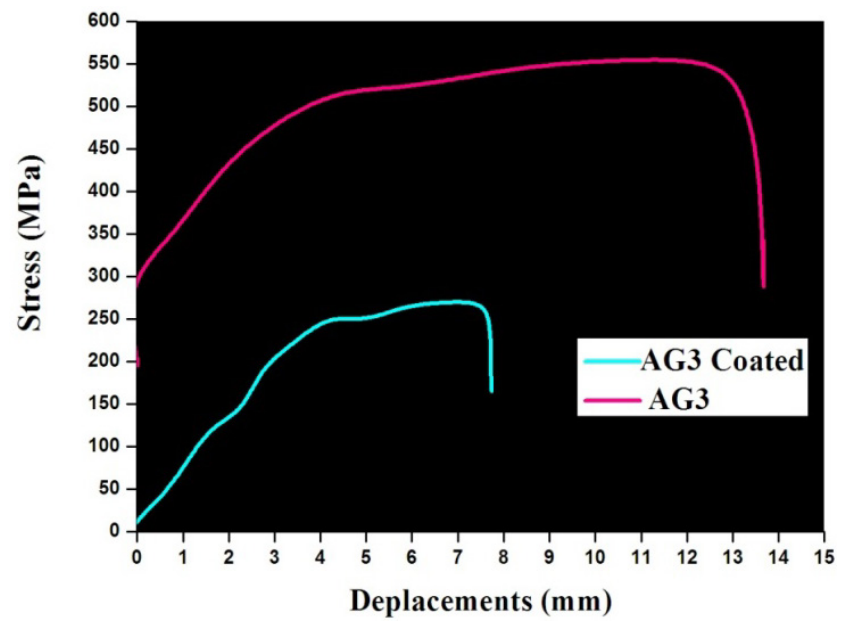

Figure 12. Comparative study of tensile test AG3 and AG3 coated.

The two curves stress-strain of AG3 uncoated and AG3 coated with $\mathrm{NiAl} /$ Thermanite showed several changes after doing a coating as regards the mechanical properties, For AG3 uncoated, the elastic limit decreased from $R_{e}=292$ $\mathrm{MPa}$ to $\mathrm{R}_{\mathrm{e}}=217 \mathrm{MPa}$. The fracture stress, fall from $\mathrm{R}_{\mathrm{p}}=$ $350 \mathrm{MPa}$ for AG3 uncoated to $\mathrm{R}_{\mathrm{p}}=327 \mathrm{MPa}$ for coated AU4G. We remark also stretching has been decreasing during time of tensile test, however, for AG3 coated we note the appearing of low variation just after the elastic limit levels.

The fluctuation presented by the curve in Figure 12 can be due to the appearance of a crack in the coating under loading $\sigma=165 \mathrm{MPa}$. Variation happened after the elastic limit (Re) for AG3 coated by NiAl / Thermanite aeronautical alloys composite and are mainly caused by priming crannie of the coating under the load of $\sigma=217 \mathrm{MPa}$ (Fig 11). These changes of stress tension in the plastic level on the AG3 coated described on the curve of the curve of Fig 11 happened when the first micro-crack appears on coating or bond coat of our mulimaterials. The decrease of the tensile strength is mainly due to the stress concentration at the cavity and porosities or heterogeneous phase present on coating created by the blasting.

Figure. 13 showed results of comparing tensile strain curve of AG3 and AU4G coated materials, we noticed that:

- The two substrates mechanical properties of materials AU4G and AG3 decrease after coating.

- The two substrates mechanical properties of materials AU4G and AG3 decrease after coating.

- $\mathrm{AU} 4 \mathrm{G}$ and AG3 coated present a variation on the plastic zone. 
- The AG3 has a great decreasing of their elastic limit $(\Delta \mathrm{Re}=75 \mathrm{MPa})$ compared to $\mathrm{AU} 4 \mathrm{G}(\Delta \mathrm{Re}=66 \mathrm{MPa})$.

- The AU4G has a biggest decreasing of their tensile strength $(\Delta \mathrm{Rp}=55 \mathrm{MPa})$ relative to $\mathrm{AG} 3(\Delta \mathrm{Rp}=$ $23 \mathrm{MPa})$.

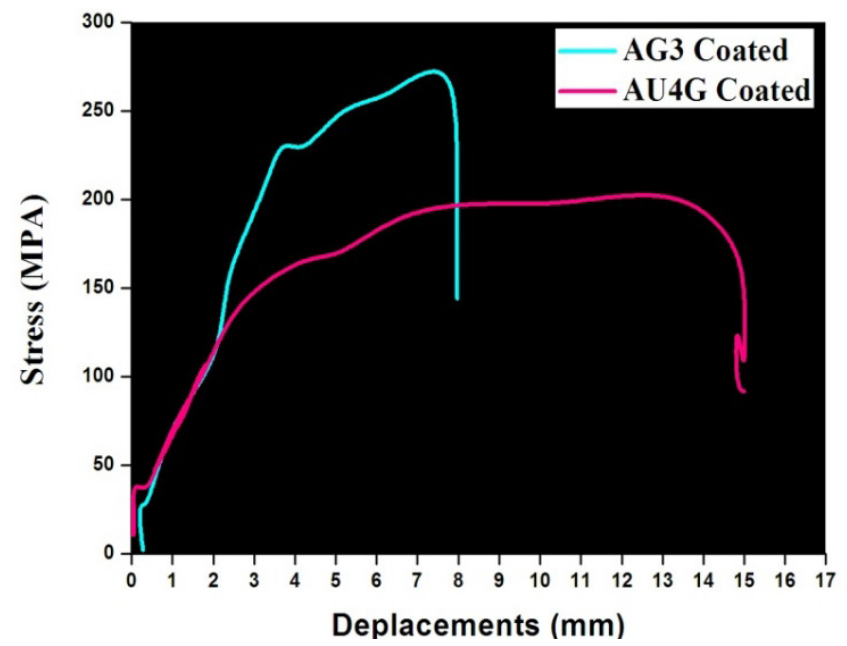

Figure 13. Tensile strain results of AG3 and AU4G coated.

The large reduction of the elastic limit of the AG3 coated compared to AU4G the coated is due to the high ductility of the AG3 compared to $A U 4 G$, this intrinsic property of materials cause in the blasting process, insert of grit particles in the substrate establishing a plastic zones. This causes a radial compression on the section and accelerates the effect of plasticizing process. The decrease of the tensile strength of the AU4G compared to that of AG3 is probably due to two parameters.

1. The reduction of the section of AG3 and AU4G after blasting and the concentration of stresses at the cavities.

2. The presence of residual stresses created when samples was blasted by corundum which increase hardening of the material and will be more brittle.

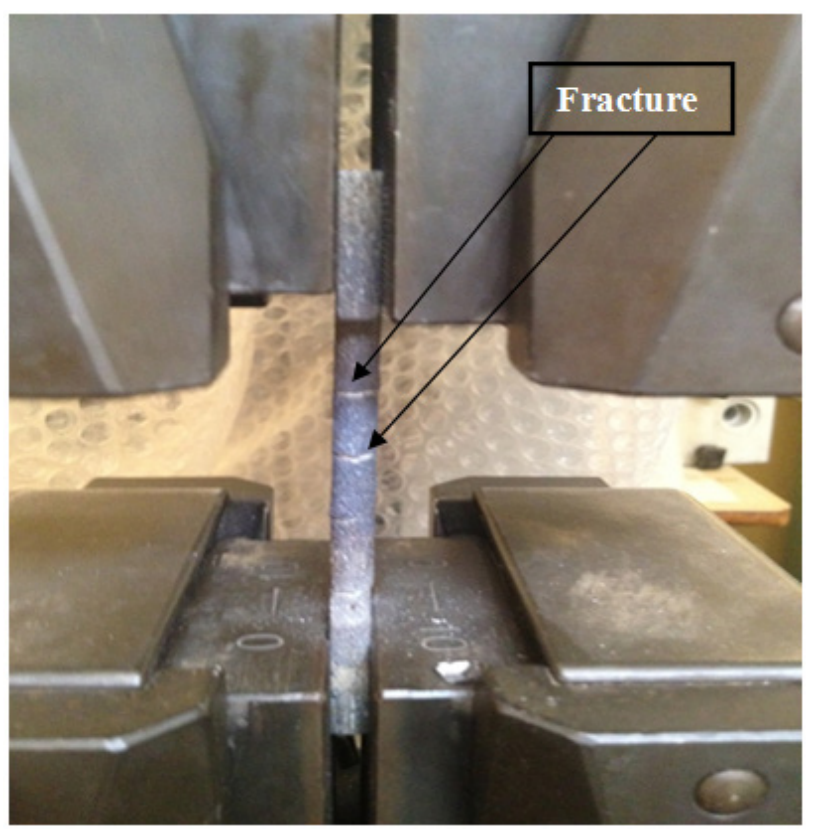

Figure 14. Tensile strain test for both system.

\subsection{Numerical Simulation of Mechanical Behaviours of Aeronautical Alloy Based Composite}

The numerical simulation with finite element of the mechanical behavior by tensile test of the developed composite System 1: Thermanite (ASTM 301) Coating / Bond coat 75E / Substrate AG3 and System 2: Thermanite (ASTM 301) Coating / Bond coat 75E / Substrate AG3 was demonstrated in Figure 15 and 16. The results of numerical simulation shows that maximum stress was mentioned in red colors and its depicted in the stress concentration under mechanical stress is localized at the ends of the working length of the specimen, which confirms the correctness of the assumed cracking mechanism of our experimental test and fracture happened between coating and substrates. We note the same mechanical behavior about the location of maximum deformation and stress concentration were noted for the composite System 1. 




Figure 15. Distributions of stress on composite $\mathrm{AU} 4 \mathrm{G} / \mathrm{NiAl} / \mathrm{Thermanite}$ after tensile test.

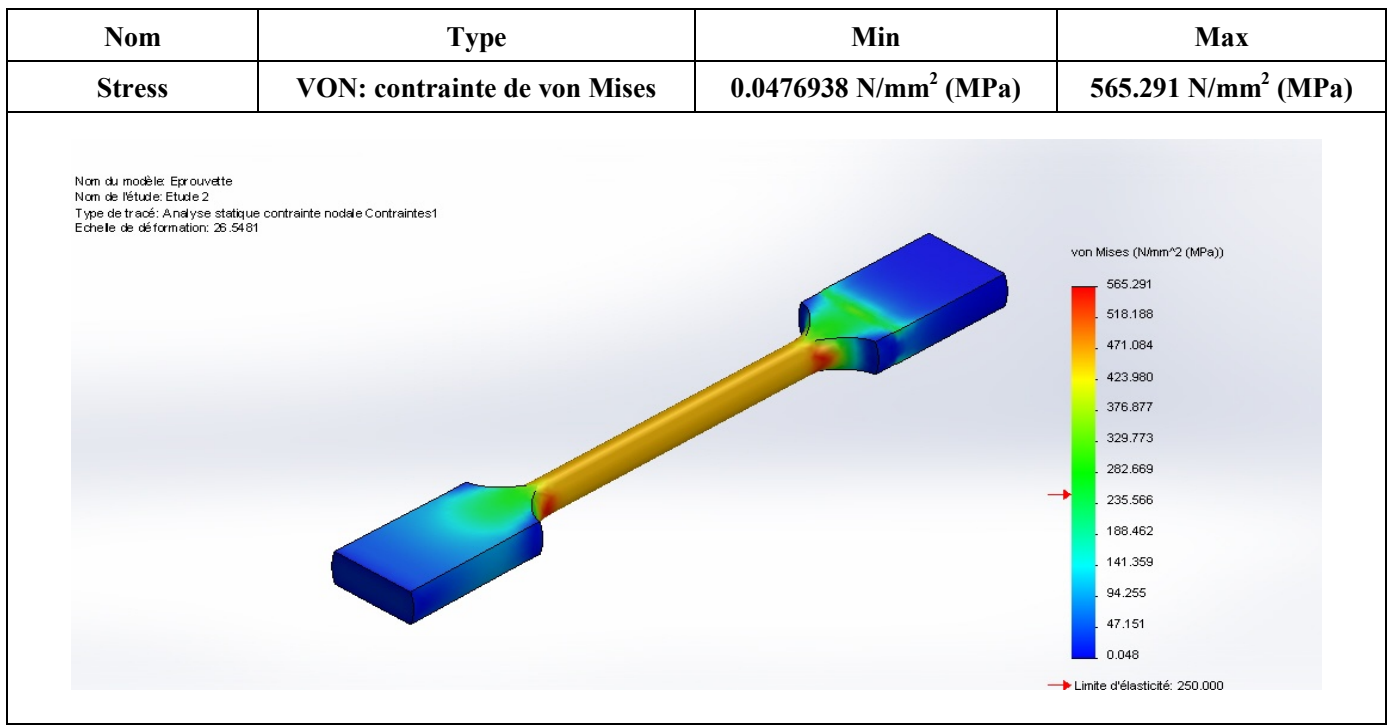

Figure 16. Distributions of stress on composite after tensile test.

\section{Conclusions}

This aim study is to produce austenitic stainless coatings thermanite (ASTM 301) onto two different substrates used on aeronautical industries which is aluminum alloys AG3 (ASTM 5754) and AU4G (ASTM 2017A) using arc spray process (ASP). In order to improve the adhesion, we used a bond coat as NiAl designed (75E) between stainless steel and coatings. On the basis of the obtained results in the present investigation, the following conclusions can be drawn:

- The substrates made of aluminum alloys are usually stripped to remove multilayer of alumina $\left(\mathrm{Al}_{2} \mathrm{O}_{3}\right)$ which have a diffusion barrier properties and disturb all multimaterials coating.
- Tensile tests showed large changes in mechanical properties of aluminum alloy after coating due to the large difference on microstructure.

- The decreasing in the elastic limit of the AG3 coated compared to the AU4G substrates is due to the high ductility of the AG3, which causes during the blasting process, a penetration of grit particles in the substrate.

- $\quad$ The large reduction of the elastic limit of the AG3 coated compared to AU4G coated is due to the high ductility of the AG3 compared to AU4G.

- The numerical simulation by finite element simulation was noted that the concentration of stresses during the tensile tests was spotted at the ends of the useful length of the test samples. 


\section{REFERENCES}

[1] J.P. Huchin, The place of thermal spraying in industry today and the prospects for the future, Proceedings of $15^{\text {th }}$ international thermal spray conference, 25-29 may, 1998.

[2] M. Ducos, J.P. Durand, Thermal coatings in Europe: a business prospective, Thermal Spray 2001: New Surfaces for New Milennium, Ohio, USA, 2001.

[3] R.W Rigney, A. Grubowski, R. McCaw, K. Scandell, Component repair and chrome plating replacement with new thermal spray in the united states navy: successes and the future, Materials Characterization, February - March 2001.

[4] A.J.S. Karema, Y. Misef, A.H. El-Sheikh, M. S. Sunjuk, Development of a new method for determination of aluminum (Al) in Jordanian foods and drinks: Solid phase extraction and adsorption of $\mathrm{Al}^{3+-} \mathrm{d}$-mannitol on carbon nanotubes, Journal of Food Composition and Analysis, Vol. 33 (1), 6-13, 2014.

[5] C.F. Struller, P.J. Kelly, N.J. Copeland, Aluminum oxide barrier coatings on polymer films for food packaging applications, Surface and Coatings Technology, Vol. 241, 130-137, 2014.

[6] C.Q. Zhang, J.D. Robson, P.B. Prangnell, Dissimilar ultrasonic spot welding of aerospace aluminum alloy AA2139 to titanium alloy TiAl6V4, Journal of Materials Processing Technology, Vol. 231, 382-388, 2016.

[7] Dinesh Kumar Koli, Geeta Agnihotri, Rajesh Purohit, Advanced Aluminum Matrix Composites: The Critical Need of Automotive and Aerospace Engineering Fields, Materials Today: Proceedings, Vol. 2, 3032-3041, 2015.

[8] R. Younes, M. A. Bradai, A. Sadeddine, Y. Mouadji, A. Bilek, A. Benabbas Microstructural and Tribological Properties of $\mathrm{Al}_{2} \mathrm{O}_{3}-13$ pctTiO 2 Thermal Spray Coatings Deposited by Flame Spraying, Metallurgical and Materials Transactions B, Vol. 46, No 5, 2394-2403, 2015.

[9] Chen Liu, Peng Liu, Zhiquan Huang, Qin Yan, Renge Guo, Dalong Li, Guirong Jiang, Dejiu Shen, The correlation between the coating structure and the corrosion behavior of the plasma electrolytic oxidation coating on aluminum, Surface and Coatings Technology, In Press, Accepted Manuscript, Available online 14 December 2015.

[10] Quanqiang An, Yedong He, De-Ren Wang, Investigation of $\mathrm{Ni}-\mathrm{P} /-\mathrm{SiC}$ coatings on aluminum alloy via aqueous cathodic plasma electrolysis, Surface and Coatings Technology, Vol.282, 115-120, 2015.
[11] Tomoji Osada, Keiji Sonoya, Takeyuki Abe, Masanobu Nakamura, Developing of the Aluminum Alloy Solid State Bonding Method in Atmosphere Using High Frequency Induction Heating and Ultrasonic Vibration, Universal Journal of Mechanical Engineering 4(1): 1-7, 2016, DOI: 10.13189/ujme.2016.040101.

[12] Keiji Sonoya, Kosuke Fukui, Motohisa Suzuki, Effect of Welding Conditions of Spot Welded Zone on the Tensile Strength about Aluminum Alloy (A6061), Universal Journal of Mechanical Engineering, pp. $8-18$ DOI: 10.13189/ujme.2016.040102.

[13] Andrei Klyndyuk, Yekaterina Chizhova, Structure and Properties of the $\mathrm{Bi} 0.85 \mathrm{Nd} 0.15 \mathrm{FeO} 3, \mathrm{BiFe} 0.85 \mathrm{Mn} 0.15 \mathrm{O} 3$, and $\mathrm{Bi} 0.85 \mathrm{Nd} 0.15 \mathrm{Fe} 0.85 \mathrm{Mn} 0.15 \mathrm{O} 3$ Multiferroics Solid Solutions, Universal Journal of Materials Science , pp. $6-13$ DOI: $10.13189 /$ ujms.2015.030102

[14] M. Magnani, P.H. Suegama, N. Espallargas, S. Dosta, C.S. Fugivara, J.M. Guilemany, and A.V. Benedetti: Influence of HVOF parameters on the corrosion and wear resistance of WC-Co coatings sprayed on AA7050 T7, Surf. Coat. Technol, Vol. 202, 4746-4757, 2008.

[15] R.J.K. Wood, Tribology of thermal sprayed WC-Co coatings, Inter. J. Refract. Met. Hard. Mater., 2010, Vol. 28, pp. 82-94.

[16] Chen Liu, Peng Liu, Zhiquan Huang, Qin Yan, Renge Guo, Dalong Li, Guirong Jiang, Dejiu Shen, The correlation between the coating structure and the corrosion behavior of the plasma electrolytic oxidation coating on aluminum, Surface and Coatings Technology, In Press, Accepted Manuscript, Available online 14 December 2015.

[17] I. Peter, M. Rosso, F.S. Gobber, Study of protective coatings for aluminum die casting molds, Applied Surface Science, Vol.358,563-571, 2015.

[18] K. Soorya Prakash, R. Sathiya Moorthy, P.M. Gopal, V. Kavimani, Effect of reinforcement, compact pressure and hard ceramic coating on aluminum rock dust composite performance, International Journal of Refractory Metals and Hard Materials, Vol. 54, 223-229, 2016.

[19] Blanca M. Rosales, Mariano Iannuzzi, Aluminum AA2024 T351 aeronautical alloy: Part 1. Microbial influenced corrosion analysis, Materials Science and Engineering: A, Vol. 472, No 1-2, 15-25, 2008.

[20] M.K. Hagnell, M. Akermo, A composite cost model for the aeronautical industry: Methodology and case study, Composites Part B: Engineering, Vol.79, 254-261, 2015.

[21] W. Van Paepegem, Fatigue testing and online inspection of carbon textile composites for aeronautical applications, Fatigue of Textile Composites, 353-382, 2015. 